\title{
The Pseudomonas aeruginosa phosphodiesterase gene $n b d A$ is transcriptionally regulated by RpoS and AmrZ
}

\author{
Katrin Gerbracht ${ }^{1}$, Susanne Zehner and Nicole Frankenberg-Dinkel*
}

Author affiliations: Technische Universität Kaiserslautern, Fachbereich Biologie, Abteilung Mikrobiologie, Paul-Ehrlich-Straße 23, D-67663 Kaiserslautern, Germany

*Correspondence: Nicole Frankenberg-Dinkel, nfranken@bio.uni-kl.de

Keywords: Pseudomonas aeruginosa, phosphodiesterase, c-di-GMP, nitric oxide, transcription

Abbreviations: c-di-GMP, bis-3,5-cyclic di-guanosine monophosphate; DGC, diguanylate cyclase; NO, nitric oxide; PDE, phosphodiesterase; RACE, rapid amplification of cDNA ends;

\section{ABSTRACT}

Pseudomonas aeruginosa is an opportunistic pathogen causing serious infections in immune compromised persons. These infections are difficult to erase with antibiotics, due to the formation of biofilms. The biofilm lifecycle is regulated by the second messenger molecule cdi-GMP (bis-3,5-cyclic di-guanosine monophosphate). $P$. aeruginosa encodes 40 genes for enzymes presumably involved in the biosynthesis and degradation of c-di-GMP. A tight regulation of expression, subcellular localized function and protein interactions control the activity of these enzymes. In this work we elucidated the transcriptional regulation of the gene encoding the membrane-bound phosphodiesterase NbdA. We previously reported a transcriptional and posttranslational role of nitric oxide (NO) on $n b d A$ and its involvement in biofilm dispersal. NO is released from macrophages during infections but can also be produced by $P$. aeruginosa itself during anaerobic denitrification. Recently however, contradictory results about the role of $\mathrm{NbdA}$ within $\mathrm{NO}$-induced biofilm dispersal were published. Therefore, the transcriptional regulation of $n b d A$ was reevaluated to obtain insights into this discrepancy. Determination of the transcriptional start site of $n b d A$ by 5'-RACE and subsequent identification of the promoter region revealed a shortened open reading frame (ORF) in contrast to the annotated one. In addition, putative binding sites for RpoS and AmrZ were discovered in the newly defined promoter region. Employing chromosomally integrated transcriptional lac $Z$ reporter gene fusions demonstrated a RpoSdependent activation and $A m r Z$ repression of $n b d A$ transcription. In order to investigate the impact of $\mathrm{NO}$ on $n b d A$ transcription, conditions mimicking exogenous and endogenous NO were applied. While neither exogenous nor endogenous NO had an influence on $n b d A$ promoter activity, deletion of the nitrite reductase gene nirS strongly increased $n b d A$ transcription independently of its enzymatic activity during denitrification. The latter supports a role of NirS in $P$. aeruginosa apart from its enzymatic function.

\section{IMPORTANCE}

The opportunistic pathogen Pseudomonas aeruginosa possesses a network of genes encoding proteins for the turnover of the second messenger c-di-GMP involved in regulatingamong others-the lifestyle switch between planktonic, motile cells and sessile biofilms. Insight into the transcriptional regulation of these genes is important for the understanding of the protein function within the cell. Determination of the transcriptional start site of the phosphodiesterase gene $n b d A$ revealed a new promoter region and consequently a

\footnotetext{
${ }^{1}$ ORCID: KG: 0000-0001-8930-3398; SZ: 0000-0003-3758-484X; NFD: 0000-0002-7757-6839
} 
bioRxiv preprint doi: https://doi.org/10.1101/2021.03.31.437996; this version posted April 1, 2021. The copyright holder for this preprint (which was not certified by peer review) is the author/funder, who has granted bioRxiv a license to display the preprint in perpetuity. It is made available under aCC-BY 4.0 International license.

44 shortened open reading frame for the corresponding protein. Binding sites for RpoS and 45 AmrZ were identified in silico and confirmed experimentally. Previously reported regulation 46 by nitric oxide was reevaluated and a strong influence of the moonlighting protein NirS 47 identified.

48 


\section{INTRODUCTION}

The opportunistic human pathogen Pseudomonas aeruginosa is able to form acute and chronic infections, the latter associated with biofilm formation (1). Within biofilms, bacteria are embedded in a self-produced matrix and are highly protected against the host immune system and antibiotic treatments $(2,3)$. Therefore, biofilm associated infections are difficult to treat and the $P$. aeruginosa biofilm lifecycle has become a well-studied topic in the last decades. Environmental cues like changes in nutrient availability or the diatomic gas nitric oxide (NO) are able to induce biofilm dispersal by promoting a switch between the sessile and planktonic lifestyle of the bacteria (4-6). In general, the biofilm lifecycle is dependent on the second messenger bis-(3,5)-cyclic diguanosine-monophosphate (c-di-GMP). However, cdi-GMP does not only regulate the biofilm lifecycle, but rather is involved in various bacterial processes e.g., motility, secretion systems, virulence and cell cycle progression (7). The intracellular level of c-di-GMP is dependent on diguanylate cyclases (DGC) that build c-diGMP from two molecules of GMP and c-di-GMP-specific phosphodiesterases (PDE) that hydrolyze c-di-GMP to either pGpG or GMP (8-12). DGC domains contain a conserved GGDEF motif whereas PDE domains contain either an EAL or HD-GYP motif. Typically, bacteria encode multiple DGC, PDE or tandem enzymes. Adjustment of the intracellular c-diGMP concentration can be achieved by regulating the production of c-di-GMP modulating proteins on different levels: transcription, post-transcription and post-translation.

On the transcriptional level, control of gene expression by various transcription factors or alternative sigma factors that react to changing environmental or growth conditions allows a temporal separation of redundant PDEs or DGCs within a bacterial cell. For instance, in $E$. coli many DGC or PDE encoding genes are under the control of the alternative sigma factor RpoS $\left(\sigma^{S}\right)$ which regulates genes for stationary growth phase or stress responses (13). Posttranscriptionally, RNA-binding proteins like CsrA of $E$. coli or RsmA of $P$. aeruginosa are able to influence the translation of DGCs or PDEs by binding to corresponding mRNAs $(14,15)$. Functional sequestration of DGCs and PDEs within a cell is achieved on the posttranslational level. For example, PDEs with EAL-motif often require dimerization to enable cdi-GMP hydrolysis (16). Binding of GTP to the GGDEF domain of the $P$. aeruginosa RbdA enhances PDE activity of the tandem protein (17). Diguanylate cyclases can be object of product feedback inhibition by binding of c-di-GMP to the I-site of the DGC domain (18). Additionally, PDE and DGC domains are often coupled to sensory domains, which allows stimulation of activity in response to environmental signals. Binding of $\mathrm{O}_{2}$ to the heme cofactor of the E. coli DosP for example is required for the proteins PDE activity (19). In the case of PA0575 of $P$. aeruginosa, binding of L-arginine to a sensory Venus flytrap (VFT) domain stimulates c-di-GMP degradation (20). Another possibility to avoid functional redundancies of c-di-GMP modulating proteins is introduced by the "fountain model". It proposes spatial sequestration of particular DCGs and PDEs within a cell and the influence on only a local c-di-GMP pool rather than on the global c-di-GMP concentration (21).

In $P$. aeruginosa, the c-di-GMP modulating network consists of 40 DGC, PDE or tandem proteins which contain both domains (22). One of them is the NO-induced biofilm dispersion locus $\underline{A}(\mathrm{NbdA})$. NbdA is a three domain protein, consisting of the membrane anchored MHYT domain, a diguanylate cyclase domain with a degenerated GGDEF motif and a phosphodiesterase domain with an EAL motif (23). NbdA was shown to be a functional phosphodiesterase, lacking DGC activity (23). The MHYT domain of NbdA is predicted to be a sensory domain for diatomic gases like oxygen, NO or carbon monoxide (CO) (24). In a previous study we observed that a $n b d A$ deletion mutant showed glutamate-induced biofilm dispersal, but was unable to disperse in response to nitric oxide. Additionally, we suggested transcriptional regulation of $n b d A$ by $\mathrm{NO}$ as $n b d A$ transcript levels were increased in NOtreated planktonic cells or dispersed cells after NO-induced dispersal when compared to 
untreated planktonic cells (23). In $P$. aeruginosa $\mathrm{NbdA}$ is not the only protein involved in NOinduced biofilm dispersal as deletion mutants of the PDEs rbdA and $\operatorname{dip} A$ both display the same phenotype as $\triangle n b d A$ (25). However, in a biofilm model on airway epithelial cells it was demonstrated that the deletion of neither $n b d A, \operatorname{rbdA}$ nor $\operatorname{dip} A$ led to a loss of biofilm dispersal in response to NO (26). These contrary findings underline, that c-di-GMP modulating proteins are tightly regulated in $P$. aeruginosa and changes in environmental conditions might impact expression or activity of those enzymes. Therefore, we decided to reevaluate the transcriptional regulation of $n b d A$ to obtain insights into this discrepancy and to gain a better understanding of NbdA's role within the c-di-GMP network of $P$. aeruginosa PAO1.

\section{MATERIAL AND METHODS}

\section{Bacterial strains and growth conditions}

All strains used in this study are listed in Table 1. If not stated otherwise, bacteria were grown in LB medium at $37^{\circ} \mathrm{C}$. For denitrification conditions, growth medium was supplemented with $50 \mathrm{mM} \mathrm{KNO}_{3}$. Pseudomonas isolation agar was used for selection of $P$. aeruginosa after mating procedures. Antibiotics were used in following concentrations: gentamicin, $10 \mu \mathrm{g} \mathrm{ml}^{-1}$ (E. coli); $75 \mu \mathrm{g} \mathrm{ml}^{-1}$ (P. aeruginosa); tetracycline, $5 \mu \mathrm{g} \mathrm{ml}^{-1}$ (E. coli); $100 \mathrm{\mu g} \mathrm{ml}^{-1}$ (P. aeruginosa).

Table 1: Strains and plasmids used in this study.

\begin{tabular}{|c|c|c|}
\hline Strain & Genotype & Reference \\
\hline \multicolumn{3}{|l|}{ E. coli } \\
\hline $\mathrm{DH} 5 \alpha$ & $\begin{array}{l}\text { F- } \phi 80 \mathrm{~d} / a c Z \Delta \mathrm{M} 15 \Delta(\text { lacZYA-argF)U169 endA1 hsdR17 deoR } \\
\text { gyrA96 thi-1 relA1 supE44 }\end{array}$ & (27) \\
\hline S17-I & recA pro thi hsdR $M^{+} \mathrm{Tp}^{r} \mathrm{Sm}^{r}$; RP4:2 Tc::Mu-Km::Tn7/Apir & (28) \\
\hline \multicolumn{3}{|l|}{ P. aeruginosa } \\
\hline$\overline{\mathrm{PAO1}}$ & wild type (wt) DSM 22644 & DSMZ \\
\hline wt mini-CTX1-lacZ & PAO1 with mini-CTX1-lacZ integrated at attB site & This work \\
\hline wt pnbdA-lacZ & PAO1 with mini-CTX1-pnbdA-lacZ integrated at attB site & This work \\
\hline$\Delta r p o s$ & rpoS deletion mutant in PAO1 background & This work \\
\hline$\Delta r p o S$ pnbdA-lacZ & $\Delta r p o S$ with mini-CTX1-pnbdA-lacZ integrated at attB site & This work \\
\hline$\Delta a m r Z$ & amrZ deletion mutant in PAO1 background & This work \\
\hline$\Delta a m r Z$ pnbdA-lacZ & $\Delta a m r Z$ with mini-CTX1-pnbdA-lacZ integrated at attB site & This work \\
\hline$\Delta$ nirs & nirS deletion mutant in PAO1 background & This work \\
\hline$\Delta$ nirS pnbdA-lacZ & $\Delta n i r S$ with mini-CTX1-pnbdA-lacZ integrated at attB site & This work \\
\hline$\Delta$ nirF & nirF deletion mutant in PAO1 background & This work \\
\hline$\Delta$ nirF pnbdA-lacZ & $\Delta n i r F$ with mini-CTX1-pnbdA-lacZ integrated at attB site & This work \\
\hline$\triangle n o r C B$ & norCB deletion mutant in PAO1 background & This work \\
\hline$\Delta$ norCB pnbdA-lacZ & $\Delta$ norCB with mini-CTX1-pnbdA-lacZ integrated at attB site & This work \\
\hline Plasmid & Relevant properties & \\
\hline pEXG2 & $\mathrm{Gm}^{r}, \mathrm{mob}, \mathrm{sacB}$ & (29) \\
\hline pEXG2- $\Delta$ rpos & truncated rpoS with 452 bp up and 439 bp downstream & This work \\
\hline pEXG2- $\Delta a m r Z$ & truncated $a m r Z$ with 484 bp up and 485 bp downstream & This work \\
\hline pEXG2- $\Delta$ nirS & truncated nirS with 448 bp up and 512 bp downstream & This work \\
\hline pEXG2- $\Delta$ nirF & truncated nirF with 517 bp up and 491 bp downstream & This work \\
\hline pEXG2- $\triangle$ norCB & truncated norCB with 452 bp up and 439 bp downstream & This work \\
\hline mini-CTX1-lacZ & Tet', lacZ, FRT site, attP site, int & (30) \\
\hline mini-CTX1-pnbdA-lacZ & transcriptional fusion of $n b d A$ promoter to lac $Z$ & This work \\
\hline pDrive & PCR cloning vector & Qiagen \\
\hline
\end{tabular}


121 Oligonucleotides used for plasmid construction are listed in Table 2. Markerless deletion 122 mutants were produced as described previously with minor modifications (31). DNA 123 fragments were generated for each deletion via splicing-by-overlap extension (SOE) PCR 124 using the corresponding Up and Down primer pairs (Table 2) and integrated into the allelic 125 exchange vector pEXG2 (29). The vector was transferred from $E$. coli S17-I to $P$. aeruginosa 126 PAO1 via biparental mating. Pseudomonas isolation agar supplemented with gentamicin was used to select cells which integrated the allelic exchange vector by homologous recombination. Those cells were streaked twice on LB medium containing sucrose $(15 \%$ $\mathrm{w} / \mathrm{v})$ to force the second crossover event. Truncation of target genes was verified via colony 130 PCR and sequencing.

131 Transcriptional $n b d A$-lacZ fusion was generated in the vector mini-CTX1-lacZ (30). A $171 \mathrm{bp}$ 132 fragment of the $n b d A$ promoter region and $279 \mathrm{bp}$ of the coding sequence was amplified via PCR and integrated in front of the promoterless lac $Z$ gene encoded on the vector. The transcriptional fusion and the empty vector control were transferred to $P$. aeruginosa strains via biparental mating and chromosomally integrated into the attB site on the genome via integrase-mediated chromosomal integration.

Table 2: Primers used in this study.

\begin{tabular}{|c|c|}
\hline Primer & Sequence $\left(5^{\prime} \rightarrow 3^{\prime}\right)$ \\
\hline \multicolumn{2}{|c|}{ deletion mutant construction } \\
\hline rpoS-Up-F & GCGCCTGCAGCAAGCTCCAGCATCTGGAGCGCTG \\
\hline rpos-Up-R & CTCCTGGAGCCCGGCATCGCGCTGAAGCGCCTGCGG \\
\hline rpoS-Down-F & GATGCCGGGCTCCAGGAGGAG \\
\hline rpoS-Down-R & GCGCCTCGAGTCGGCCGTTTTGCCTCAAACGGAA \\
\hline rpoS-seqF & CTAGAATCGCGCGCGCTTAGCCG \\
\hline rpos-seqR & TGCTCGGGGCCGTCGTCTGTTC \\
\hline amrZ-Up-F & GCGCAAGCTTGATGCACCGATCAACGC \\
\hline amrZ-Up-R & CTCCGCATCGTGTGCGGTAGGAGTTGCCTGTTTCA \\
\hline amrZ-Down-F & GCACACGATGCGGAG \\
\hline amrZ-Down-R & GCGCGAATTCTCAGGTTGACCAGCAGAAC \\
\hline amrZ-seqF & ACCCAGCACGTCGAT \\
\hline amrZ-seqR & GGAATGACTCCGGGCT \\
\hline nirS-Up-F & GCGCCTGCAGAAGAGGACAGGCGAACGTCAGCGC \\
\hline nirS-Up-R & GGCACCTTGCTCGCCTCGCGGCTGATCACCCCGACCGGTAAG \\
\hline nirS-Down-F & CGAGGCGAGCAAGGTGCCCAC \\
\hline nirS-Down-R & GCGCCTCGAGCCAGGTAGCAGATACCGCCTTCGCG \\
\hline nirS-seqF & TGAGGAGAAGCGGCGCGAGGGGA \\
\hline nirS-seqR & GTAGTCGAAGCGCAACGCGACGAAACG \\
\hline nirF-Up-F & GCGCCTGCAGCAGGTAGCGCAGGTGTTGCCG \\
\hline nirF-Up-R & AGCCAGCAGCCGCCCTTGCCGAGCGGCATCTTCTTCAGCCAC \\
\hline nirF-Down-F & CAAGGGCGGCTGCTGGCTACA \\
\hline nirF-Down-R & GCGCCTCGAGCGCCGAAGCGGAACTCGCG \\
\hline nirF-seqF & ATGGCCACATCGGCAGGCGAC \\
\hline nirF-seqR & GCTCCCCCCTACGAGGAACCGTG \\
\hline norCB-Up-F & GCGCAAGCTTTGCTGGCGCCGGTGTTATACGC \\
\hline norCB-Up-R & TAGGCGACCAGGCCGATGAGCCCGCCGAAATAGATGTTCCTGGCC \\
\hline norCB-Down-F & CTCATCGGCCTGGTCGCCTACC \\
\hline norCB-Down-R & GGGGAATTCATTTCCAGTTCGGCGTCTGCCGC \\
\hline norCB-seqF & TCATCGGCGACGGCATGGACC \\
\hline norCB-seqR & ATCGGTTGCAGCAGCACGTGG \\
\hline pEXG2-seqF & CGACCTCATTCTATTAGACTCTCGTTTGGATTGC \\
\hline pEXG2-seqR & GTTCGCTCGCGTATCGGTGATTCATTCTG \\
\hline \multicolumn{2}{|l|}{ pnbdA-lacZ fusion } \\
\hline pnbdA-lacZ-F & GCGCGAATTCATGCCTTTTCTCCCCGGGAAAATGC \\
\hline pnbdA-lacZ-R & GCGCGGATCCCAGGTCGTAGCGCAGGGCGA \\
\hline lacZ-rev & GGATTTCCTTACGCGAAATACGGG \\
\hline seq3miniCTXlacZ & ATCCACCGGCGCGCGTAATACG \\
\hline \multicolumn{2}{|l|}{ RT-PCR } \\
\hline$n b d A-\mathrm{RT} 1-\mathrm{F}$ & TTCCTCGACCTCGATCACTT \\
\hline$n b d A-\mathrm{RT} 1-\mathrm{R}$ & TGGGTTCCTTCATCTTCTGC \\
\hline recA-RT1-F & GACCGAGGCGTAGAACTTCA \\
\hline recA-RT1-R & CAACTGCCTGGTCATCTTCA \\
\hline 5'-RACE primer & \\
\hline SP1_nbdA: & ATGGCTGGTAGTACTGGGTGGC \\
\hline
\end{tabular}


SP3 Bg/ll nbdA

Oligo (dT) anchor primer

anchor-1 primer

${ }^{*} \mathrm{~V}=\mathrm{A}, \mathrm{C}$ or $\mathrm{G}$

\section{$\beta$-Galactosidase assay} listed in Table 2. sequenced.

For measurements of promoter activity the $\beta$-galactosidase assay protocol of Miller (32) was modified as follows. Overnight cultures containing the promoter-lac $Z$ fusion were diluted to an $\mathrm{OD}_{600}$ of 0.01 in $20 \mathrm{ml}$ LB with respective antibiotics. In exponential $(4 \mathrm{~h})$ and early stationary growth phase $(7 \mathrm{~h}) \mathrm{OD}_{600}$ was measured and cells of $100 \mu$ l culture were harvested by centrifugation. Cells were resuspended in $800 \mu \mathrm{l}$ Z-buffer $\left(60 \mathrm{mM} \mathrm{Na} \mathrm{HPO}_{4} \times 7 \mathrm{H}_{2} \mathrm{O}\right.$; $40 \mathrm{mM} \mathrm{NaH} \mathrm{PO}_{4} \times \mathrm{H}_{2} \mathrm{O} ; 10 \mathrm{mM} \mathrm{KCl} ; 1 \mathrm{mM} \mathrm{MgSO}_{4} \times 7 \mathrm{H}_{2} \mathrm{O} ; 50 \mathrm{mM} \beta$-mercaptoethanol). To permeabilize the cells $25 \mu \mathrm{l}$ of $0.1 \%(\mathrm{w} / \mathrm{v})$ sodium-dodecyl sulfate (SDS) and $25 \mu \mathrm{l}$ chloroform were added. After 5 min incubation $200 \mu \mathrm{l}$ of $4 \mathrm{mg} / \mathrm{ml}$ ortho-nitrophenyl- $\beta$-Dgalactosid (ONPG) were added to the mixture at $37^{\circ} \mathrm{C}$ to start the reaction. When $\beta$-galactosidase activity was indicated by a color change due to the formation of the yellow colored product ortho-nitrophenol, the reaction was stopped by addition of $500 \mu \mathrm{l} 1 \mathrm{M}$ $\mathrm{Na}_{2} \mathrm{CO}_{3}$. Cell debris was precipitated by centrifugation and product formation was measured in the supernatant at $O D_{420}$. The activity of $\beta$-galactosidase was calculated as follows: Miller units $(\mathrm{MU})=\left(\mathrm{OD}_{420} /\left(\mathrm{OD}_{600}{ }^{*}\right.\right.$ volume ${ }^{*}$ incubation time $\left.)\right){ }^{*} 1000$.

\section{RNA extraction and semi quantitative RT-PCR}

Bacteria were grown to exponential and early stationary phase as described above. To prevent RNA degradation, cells of an equivalent of $\mathrm{OD}_{600}=1$ in $1 \mathrm{ml}$ were mixed with $100 \mu \mathrm{l}$ RNA stop solution $\left(5 \%(\mathrm{v} / \mathrm{v})\right.$ phenol in ethanol). Cell pellets were stored at $-80{ }^{\circ} \mathrm{C}$ or used directly for RNA extraction. RNA was extracted by enzymatic lysis according to Qiagen RNA protect handbook and further purified with the RNeasy Plus Mini kit (Qiagen) following the suppliers instruction. Extracted RNA was transcribed into cDNA using ProtoScript II Reverse Transcriptase (New England Biolabs) according to the manufacturers' protocol. $2.5 \mathrm{ng}$ of cDNA were used as template for $25 \mu \mathrm{l}$ semi quantitative RT-PCR reaction. Used primers are

\section{Determination of transcriptional start sites by 5'-RACE}

$P$. aeruginosa cells were inoculated 1:100 from an overnight culture in LB medium and incubated $5 \mathrm{~h}$ at $37^{\circ} \mathrm{C}$. Total RNA isolation was performed as previously described (33). Primers used for $5^{\prime}$-RACE are listed in Table 2. cDNA was synthesized at $42^{\circ} \mathrm{C}$ for 60 min with M-MLV-RT (Promega) using gene-specific primer SP1_nbdA. The cDNA was treated with shrimp alkaline phosphatase (New England Biolabs) and purified with MinElute kit (Qiagen). A deoxyadenosine tail was added to the 3' end of the cDNA using terminal transferase (Thermo Fisher Scientific). Second-strand synthesis was performed with an oligo (dT) anchor primer. The obtained double-stranded DNA was amplified with the anchor-1 primer and nested gene-specific primer SP3_Bgll $n b d A$. The resulting PCR product was purified (MinElute kit, Qiagen) and cloned in pDrive using the Qiagen PCR cloning kit (Qiagen). For the determination of the transcriptional start site 10 individual clones were 


\section{RESULTS}

179

180

181

182

183

184

185

186

187

188

189

190

191

192

193

194

\section{Determination of transcriptional start site of $n b d A$ reveals a regulatory region with RpoS and AmrZ binding sites}

Automated annotation of the genome sequence of PAO1 predicted the open reading frame (ORF) for $n b d A$ to code for 783 amino acid residues. Sequence alignments of the translated sequence with proteins containing $\mathrm{N}$-terminal MHYT-domains revealed a long $\mathrm{N}$-terminal extended region for $\mathrm{NbdA}$. This incited us to analyze the gene region in more detail. In close proximity to the annotated start codon no ribosomal binding site (RBS) could be detected. A 5'-RACE PCR experiment revealed the transcriptional start site of $n b d A 103$ nucleotides downstream of the computationally annotated translation start (Fig. 1). The nearest potential translational start site is 170 nucleotides downstream of the previously annotated translation start and possesses a bona fide ribosome binding site. This results in a shorter ORF coding for a 726 amino acid protein whose $\mathrm{N}$-terminus aligns well with the N-termini of other MHYTdomain proteins. With the new defined transcriptional start, the $n b d A$ promoter region was analyzed. Conserved binding sites for the alternative sigma factor RpoS $\left(\sigma^{S}\right)$ and the transcription factor AmrZ were identified $(34,35)$.

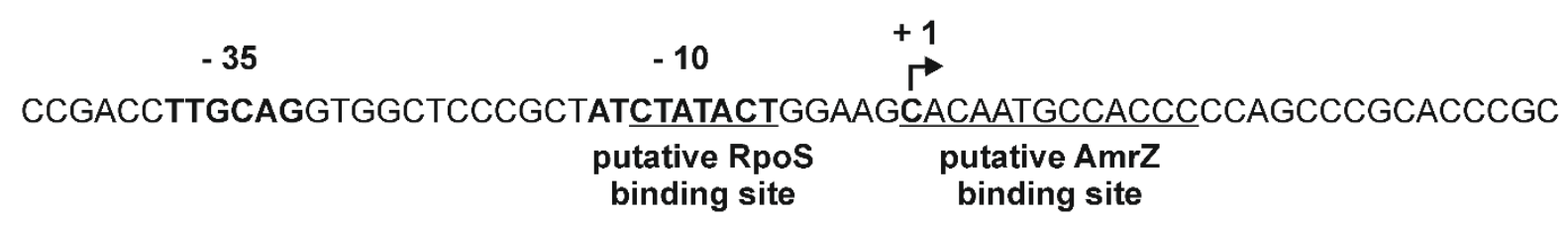

GCCGTCCGCGGGTTTTCCGTGTCCAGGGAGACACCGCTATGGATTGGCAAGGCCTG RBS

Fig. 1: Reannotation of the promoter region of $n b d A$ with the experimentally determined transcriptional start site. $5^{c}-\mathrm{RACE} P C R$ experiments revealed transcriptional start site of the $n b d A$ gene with a $C(+1), 171$ nucleotides downstream from the previously annotated ORF start site (Pseudomonas database (36)). The promoter region of $n b d A$ was reanalyzed and reveals deduced binding sequences for the alternative $\sigma$-factor RpoS and the transcriptional regulator AmrZ.

The binding motif for RpoS lies in the -10 region of the $n b d A$ promoter. The predicted AmrZ binding sequence covers the transcriptional start site of $n b d A$ indicating a repressor function. In order to investigate the role of the alternative sigma factor RpoS and the transcription factor AmrZ on $n b d A$ expression, the promoter region of $n b d A$ was transcriptionally fused to the reporter gene lac $Z$ and integrated in the $\varphi C T X$ attachment site of PAO1 wt, $\triangle$ rpos and $\triangle a m r Z$. Activity of the $\beta$-galactosidase in the respective strains was determined in exponential $(4 \mathrm{~h})$ and early stationary $(7 \mathrm{~h})$ growth phase. In the wt strain, a 4-fold increase in $n b d A$ transcription was observed when cells entered the early stationary phase, which suggests transcriptional activation by RpoS. Deletion of rpoS resulted in a loss of $n b d A$ promoter activity in both, exponential and stationary growth phase (Fig. 2), confirming the role of RpoS as transcriptional activator of $n b d A$. In the $\Delta a m r Z$ strain a strong increase of $n b d A$ promoter activity was observed in both, exponential and early stationary growth phase (Fig. 2). AmrZ is therefore likely acting as a transcriptional repressor for $n b d A$. 


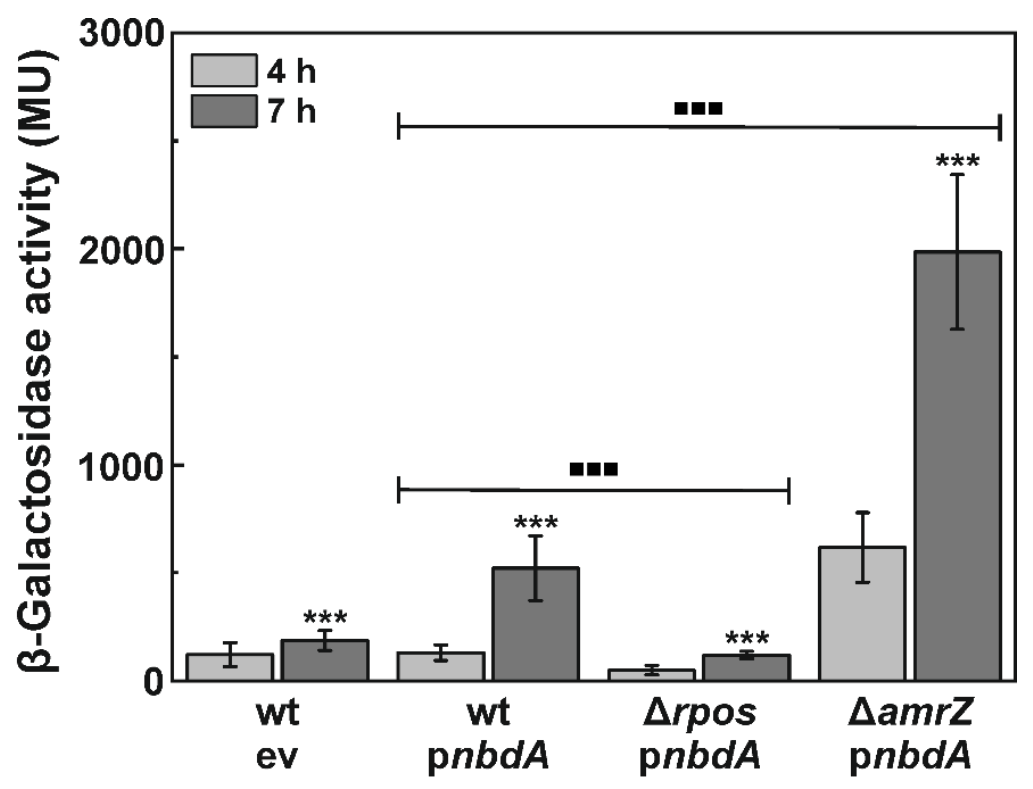

Fig. 2: Transcription of $n b d A$ is activated by RpoS and repressed by AmrZ. Promoter activity was determined with integrated pnbdA-lac Z fusions in late exponential $(4 \mathrm{~h})$ and early stationary $(7 \mathrm{~h})$ growth phase in wild type (wt) and deletion mutants $\Delta r p o S$ and $\triangle a m r Z$. Additionally, the wt with integrated empty vector (ev) was tested for background $\beta$-galactosidase activity. The assay was performed in triplicates. Significant changes between 4 and $7 \mathrm{~h}$ samples are marked with *. Significant changes in $n b d A$ expression levels between deletion mutant strains and the corresponding wt sample are marked with - $\left({ }^{\star * *} P<0.001\right.$, determined by Student's T-test).

As there is a sharp oxygen gradient present in biofilm macrocolonies (37), $\mathrm{O}_{2}$ might also have an impact on the expression of genes active in biofilms. Although there is no hint for an FNR-like, ANR, or DNR regulator binding site in the promoter region, we tested $n b d A$ promoter activity also under anaerobic conditions. Induction of the $n b d A$ promoter was observed when cultures reached stationary phase in all tested strains, similarly to the aerobic growth conditions (Fig. 3). Overall, the values for promoter activity under oxygen limitation were significantly lower than in aerobic conditions. The $n b d A$ promoter activity in the $a m r Z$ deletion strain was significantly increased compared to the wild-type background. Therefore, AmrZ seems to repress $n b d A$ transcription similarly in aerobic and anaerobic growth conditions. 


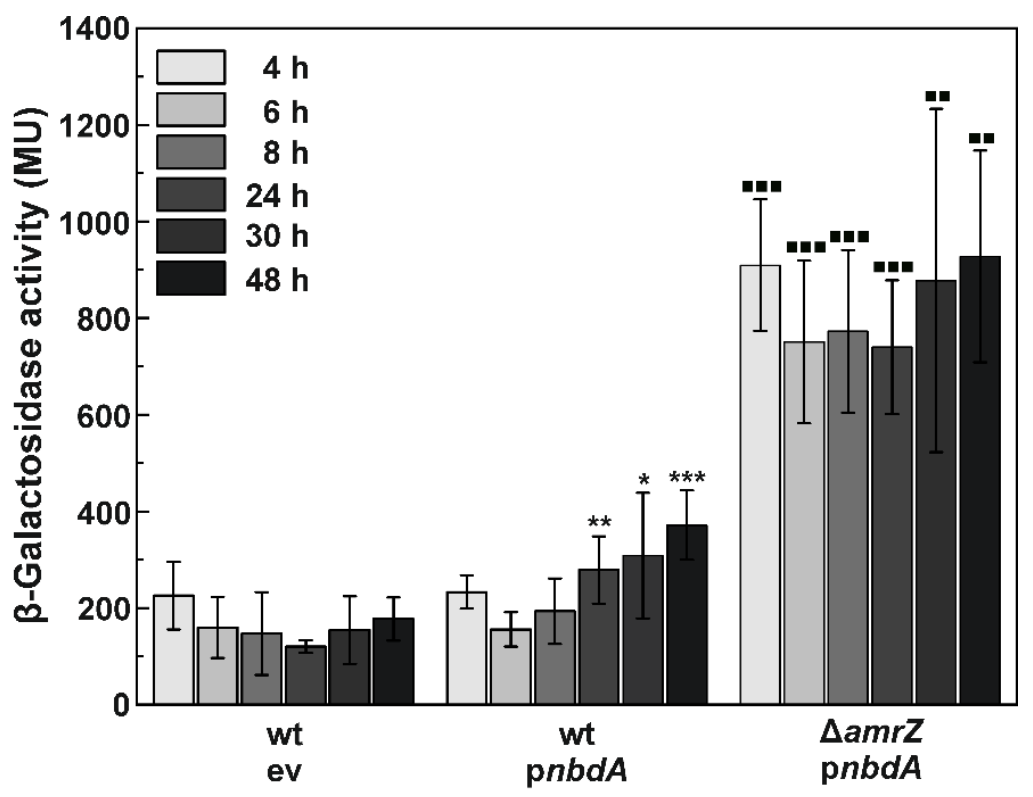

Fig. 3: Under oxygen limitation, transcription levels of $n b d A$ are induced in stationary growth phase. PAO1 wt and $\triangle a m r Z$ containing an integrated pnbdA-lacZ fusion and the empty vector control (ev) were grown anaerobically for $48 \mathrm{~h}$ in LB medium with $50 \mathrm{mM} \mathrm{NaNO}_{3}$. Inoculation of cultures was performed aerobically therefore the first hours of growth were required to consume remaining oxygen. Expression levels were determined by $\beta$-galactosidase assays in triplicates. Significant changes in $n b d A$ transcription levels of wt samples to the $6 \mathrm{~h}$ sample are marked with *. Significant changes in $n b d A$ transcription level of $\Delta a m r Z$ samples to corresponding wt levels are marked with $\mathbf{m}$. ( $\mathrm{P}<0.05$; ${ }^{* *} \mathrm{P}<0.01$; ${ }^{* \star *} \mathrm{P}<0.001$, determined by Student's $\mathrm{T}$ test).

\section{Impact of nitric oxide on the transcription of $n b d A$}

We previously reported increased amounts of $n b d A$ transcript in dispersed cells after NOinduced biofilm dispersal compared to untreated planktonic cells and suggested a NOdependent transcriptional regulation of $n b d A(23)$. In the light of divergent results on the role of $n b d A$ in NO-induced biofilm dispersion $(23,26)$ we wanted to clarify the regulation of $n b d A$ in response to endogenous and exogenous NO. During infections, host macrophages release exogenous $\mathrm{NO}$ in order to eradicate bacteria (38). However, under anaerobic conditions, $P$. aeruginosa is able to form endogenous NO during denitrification. Within the denitrification process, nitrite is reduced by the nitrite reductase NirS into NO, which is then further reduced to nitrous oxide by $\operatorname{NorCB}(39,40)$. For its enzymatic activity, NirS requires the incorporation of a heme $d_{1}$ cofactor which is synthesized by NirF (41). Interruption of the denitrification pathway by deletion of the nor $C B$ gene leads to the accumulation of intrinsic NO under denitrifying conditions (4). A $\triangle$ norCB strain containing the $n b d A$ promoter lacZfusion was used to analyze the effect of endogenous NO on $n b d A$ transcription. Deletion mutants of nirS and nirF, both unable to form endogenous NO, served as negative controls. The denitrification deficient strains showed normal growth under aerobic conditions in LB medium complemented with $\mathrm{KNO}_{3}$ (Fig. 4A). In contrast, under anaerobic denitrifying conditions the growth of PAO1 $\Delta$ nirS and $\Delta$ nirF was reduced compared to the wt PAO1 (Fig. $4 \mathrm{~B})$. The $\triangle$ nor $C B$ strain was no longer able to grow. For the analysis of $n b d A$ transcription, the strains containing the $n b d A$ promoter lacZ-fusion were grown under aerobic/microaerobic conditions and B-galactosidase assays were performed with samples of the exponential $(4 \mathrm{~h})$ and early stationary growth phase (7 h) (Fig. 4C). Compared to the wt, the nirS deletion had a severe activating effect on $n b d A$ expression in both, exponential and early stationary growth phase. Surprisingly, $n b d A$ transcription in the $\Delta$ nirF strain, which produces an enzymatically inactive NirS, was not as high as in the $\Delta$ nirS strain but comparable to the level of transcription in the wt background. The transcription of $n b d A$ in the $\triangle$ norCB strain is 
slightly decreased compared to the wt background. Due to the impaired growth in anaerobic conditions of $\triangle$ norCB strain, we could not test for the effect of accumulation of endogenous $\mathrm{NO}$ on $n b d A$ transcription. In order to confirm the findings for the $\Delta$ nirS strain, a semi quantitative RT-PCR experiment was performed with CDNA of wt and deletion mutant in both tested growth phases (Fig. 4D). While the control PCR with recA primers showed equally strong bands for all samples, $n b d A$ expression in the wt in exponential growth phase was weaker than in early stationary growth phase. In the nirS deletion strain, there was more transcript of $n b d A$ detectable than in wt, which is consistent to the findings of the $\beta$ galactosidase assay.
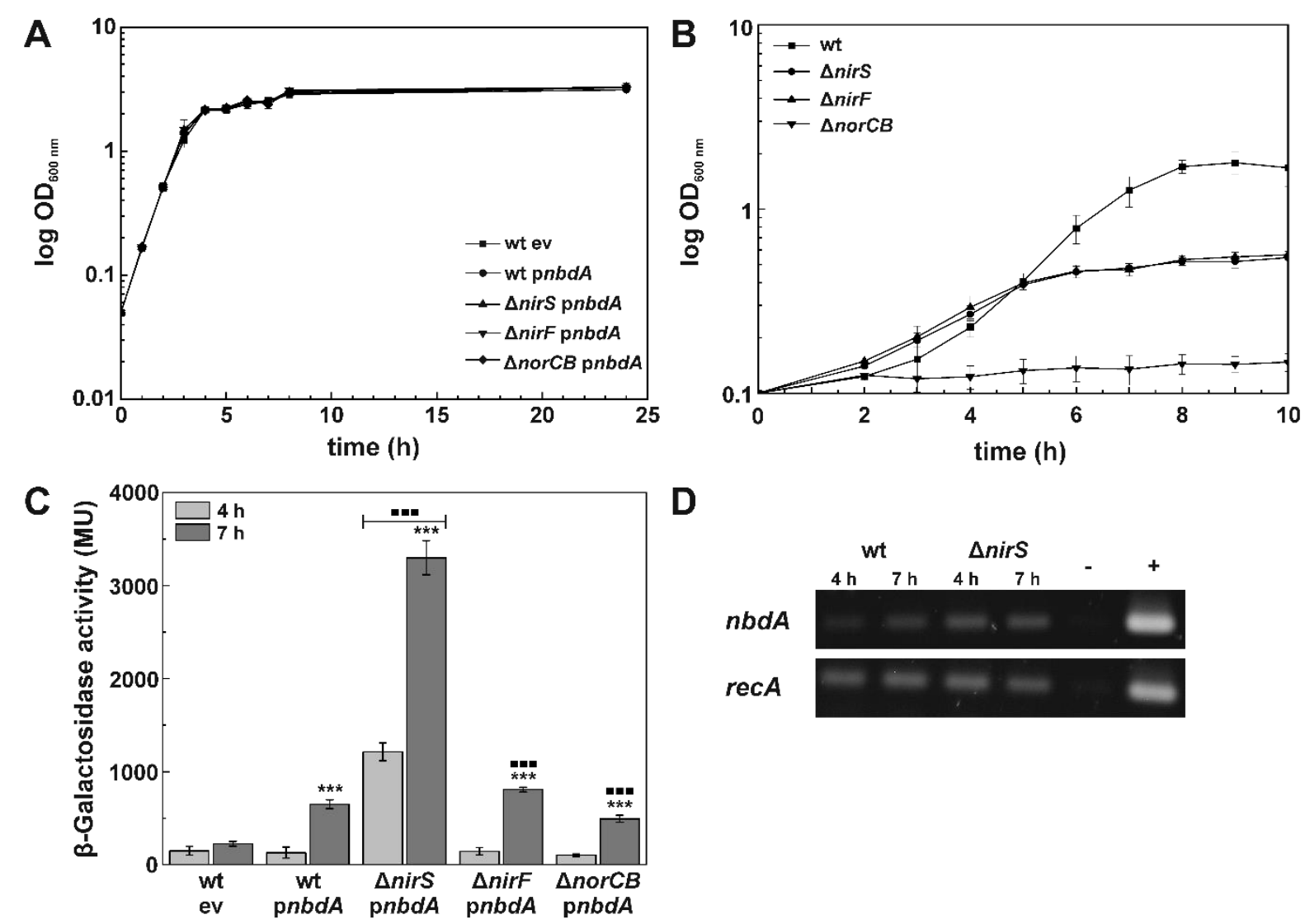

D

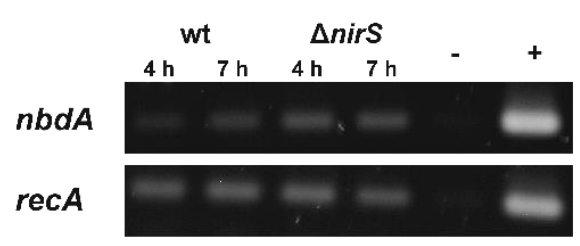

Fig. 4: $P$. aeruginosa wild type (wt), $\triangle$ nirS, $\triangle$ nirF, and $\triangle n o r C B$ strains harboring a transcriptional $p n b d A$ lacZ-fusion and the wt containing the "empty vector" control (ev) were grown in LB supplemented with $50 \mathrm{mM} \mathrm{KNO}$. [A] Growth in glass culture flasks was monitored during $24 \mathrm{~h}$ in three biological replicates. [B] Anaerobic growth in LB medium supplemented with $50 \mathrm{mM} \mathrm{KNO}_{3}$ of the wt and deletion mutants was analyzed in sealed bottles for $10 \mathrm{~h}$ in biological triplicates. [C] $\beta$-galactosidase activity was determined from cells aerobically/ microaerobically grown to exponential $(4 \mathrm{~h})$ and early stationary phase $(7 \mathrm{~h})$. All assays were performed in triplicates. Significant changes between 4 and $7 \mathrm{~h}$ samples are marked with *. Significant changes in $n b d A$ expression levels between deletion mutant strains and the corresponding wt sample are marked with $\mathbf{m}$. ${ }^{\star * *} \mathrm{P}<0.001$, determined by Student's T-test). [D] Semi quantitative RT-PCR for nbdA transcript and the control recA was performed. RNA was extracted from wt and $\Delta$ nirS strains after 4 and $7 \mathrm{~h}$ growth in LB medium.

In addition to the influence of intrinsic nitric oxide on $n b d A$ transcription, the effect of exogenous NO was investigated. Therefore, the PAO1 wt harboring the nbdA-lacZ fusion was grown with increasing amounts of the NO donor sodium nitroprusside (SNP) and $n b d A$ promoter activity was determined by $\beta$-galactosidase activity (Fig. $5 \mathrm{~A}$ ). Low concentration of added SNP to the growth medium had no effect on $n b d A$ promoter activity, whereas the addition of $500 \mu \mathrm{M}$ SNP led to a decrease of $n b d A$ transcription. This effect is comparable to the observed decrease of $n d b A$ transcription in the NO-accumulating strain $\triangle$ norCB. As $P$. aeruginosa is able to detoxify nitric oxide via flavohemoglobin $(42,43)$ under aerobic conditions, the influence of short-term NO stress on $n b d A$ transcription was analyzed. 
Therefore, PAO1 wt nbdA-lacZ was grown to stationary phase in LB and then stressed for 30 min by the addition of $500 \mu \mathrm{M}$ SNP. Compared to the untreated control, no changes in the $n b d A$ promoter activity were observed (data not shown).

302
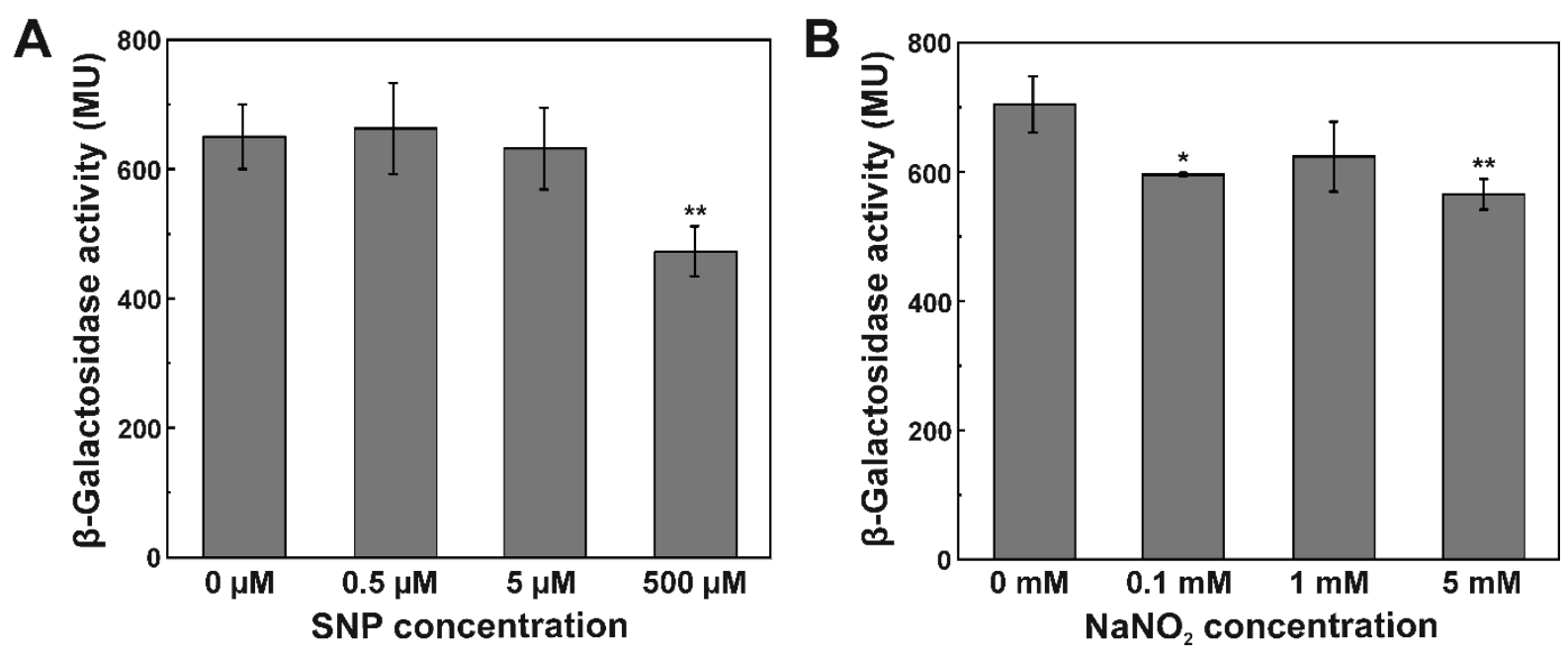

Fig. 5: Analysis of transcriptional activity of $n b d A$ promoter in response to exogenic $\mathrm{NO}$ and $\mathrm{NO}_{2} \mathrm{Sources}$ Reporter strain $\mathrm{PAO} 1$ wt::pnbdA-lacZ was grown to early stationary phase $(7 \mathrm{~h})$ in medium containing increasing amounts of the NO-releasing compound sodium nitroprusside (SNP) $[\mathbf{A}]$ or $\mathrm{NaNO}_{2}[\mathrm{~B}]$. $\beta$-galactosidase activity was measured in triplicates $\left({ }^{*} \mathrm{P}<0.05\right.$; ${ }^{* *} \mathrm{P}<$ 0.01 , determined by Student's T-test).

In order to figure out whether the strong increase of $n b d A$ expression in the $\Delta$ nirS strain was based on nitrite accumulation due to interrupted denitrification (4), $\beta$-galactosidase assays were performed with different amounts of nitrite in the growth medium (Fig. 5B). None of the tested nitrite concentrations had a comparable effect on the $n b d A$ promoter as the deletion of nirS. The addition of nitrite to the medium rather decreased expression of $n b d A$ slightly, probably due to bacteriostatic effect of nitrite. 


\section{DISCUSSION}

In this study we analyzed the transcriptional regulation of $n b d A$ coding for the phosphodiesterase $\mathrm{NbdA}$, involved in the c-di-GMP modulating network in $P$. aeruginosa. Determination of the transcription initiation site of $n b d A$ by 5 '-RACE revealed an erroneous annotation of the ORF in the databases. A new promoter region was identified, containing putative binding sites for RpoS and AmrZ. Gene expression of $n b d A$ was shown to be activated in stationary growth phase by the alternative sigma factor RpoS $\left(\sigma^{S}\right)$. A further level of regulation is introduced through the repression by the ribbon-helix-helix transcription factor AmrZ. Oxygen limitation, supplementation with nitrite, and endogenous or exogenous nitric oxide did not affect the transcription of $n b d A$. Surprisingly, deletion of the nitrite reductase NirS showed a strong activating effect on $n b d A$ transcription, while a strain with an enzymatically inactive NirS $(\triangle$ nirF) showed no transcriptional changes.

The sigma factor RpoS is known as the master regulator of gene expression during stationary growth phase. Furthermore, it is responsible for the activation of genes in response to different stresses, e.g. starvation, heat, oxygen or osmotic stress (44-46). In some Proteobacteria, RpoS is additionally involved in regulation of virulence genes, quorum sensing and motility (47-50). In E. coli, RpoS has been shown to play an important role in biofilm maturation, architecture and density (51-53). This link is partly due to the involvement of RpoS in the c-di-GMP regulatory network of E. coli. In the E. coli K12 strains MC4100 and W3110 a great subset of GGDEF/EAL-domain encoding genes was identified to be under control of RpoS $(54,55)$. Similarly, in Pseudomonas sp. several genes related to biofilm formation, maturation and architecture were shown to be regulated by RpoS $(56,57)$. A global analysis of $P$. aeruginosa PA14 revealed that 30 out of 40 genes encoding for c-diGMP modulating enzymes, are either transcriptionally activated or repressed by RpoS (Table 3 and references therein). Thus, similar to $E$. coli, RpoS-dependent regulation significantly affects the c-di-GMP network of $P$. aeruginosa. RpoS regulated genes are often subject to further regulatory mechanisms. Activator or repressor proteins might be involved, as well as post-transcriptional regulation. The ps/ operon coding for matrix polysaccharide biosynthesis genes in $P$. aeruginosa is controlled transcriptionally by RpoS and post-transcriptionally by RsmA (58). In P. putida KT2440 the exopolysaccharide cluster pea is activated by RpoS and repressed by AmrZ (59). Actually, when we evaluated and compared the data of the PA14 RpoS regulon (35) and the PAO1 AmrZ regulon (34) we found 18 out of 40 genes encoding for c-di-GMP modulating enzymes in $P$. aeruginosa presumably regulated by both proteins, RpoS and AmrZ (Table 3, (34, 35)).

The transcriptional regulator AmrZ controls a large regulon containing 398 gene regions in PAO1. Transcription of $a m r Z$ itself is in a great extend dependent on the alternative sigma factor AlgT $\left(\sigma^{22}\right)$ which is known to regulate coversion to mucoidity and stress responses in $P$. aeruginosa $(60,61)$. AmrZ was shown to regulate genes important for $P$. aeruginosa virulence, including type IV pili, extracellular polysaccharides, and the flagellum (34). It particularly influences genes required for alginate production and twitching-motility $(34,62-$ 64). Within the c-di-GMP network of $P$. aeruginosa, AmrZ activates transcription of 14 genes and represses 10 genes encoding GGDEF/EAL-domain proteins ((34), Table 3). With these numbers, AmrZ appears to be one of the major regulators for genes coding for c-di-GMP modulating enzymes in $P$. aeruginosa, possibly affecting the cellular c-di-GMP level. This role for AmrZ was previously also observed in P. fluorescens F113, where the cellular c-diGMP level was affected by AmrZ through the regulation of a complex network of genes encoding DGCs and PDEs (65). From our work we conclude that $n b d A$ transcription is repressed by $A m r Z$ during aerobic as well as anaerobic planktonic growth while a condition in which the $n b d A$ promoter is de-repressed remains uncertain. Repression through $A m r Z$ is described to be dependent on the C-terminus mediated tetramerization of the protein (66). In 
some cases, e.g. pilA repression, the expression level of AmrZ plays an important role for its function, as binding efficiency of $A m r Z$ to different promoter regions differs (64). Additionally, a competition of the activator RpoS and the repressor $A m r Z$ upon binding to the $n b d A$ promoter might be possible.

Table 3: Genes coding for c-di-GMP modulating proteins in PAO1 and PA14 and their association to RpoS or AmrZ regulon. Data extracted from Schulz 2015, and Jones 2014.

RpoS regulon was analyzed in $P$. aeruginosa PA14 via mRNA profiling of $\triangle$ rpoS vs. wt (35). AmrZ regulon was measured via RNA-Seq experiments in a PAO1 amrZ complementation strain vs. $\triangle a m r Z$ (34). GGDEF: diguanylate cyclase domain, EAL: phosphodiesterase domain, GGDEF-EAL: tandem diguanylate cyclase - phosphodiesterase domain, HD-GYP 375 phosphodiesterase domain.

376 + activation; - repression; none: is not part of the indicated regulon.

\begin{tabular}{|c|c|c|c|c|c|}
\hline $\begin{array}{c}\text { PAO1 } \\
\text { gene locus }\end{array}$ & $\begin{array}{c}\text { PA14 } \\
\text { gene locus }\end{array}$ & name & domain(s) & RpoS regulation & AmrZ regulation \\
\hline PA0169 & PA14_02110 & $\operatorname{sia} D$ & GGDEF & - & - \\
\hline PA0285 & PA14_03720 & & GGDEF-EAL & none & - \\
\hline PA0290 & PA14_03790 & & GGDEF & none & none \\
\hline PA0338 & PA14_04420 & & GGDEF & - & - \\
\hline PA0575 & PA14_07500 & $r m c A$ & GGDEF-EAL & + & none \\
\hline PA0847 & PA14_53310 & & GGDEF & + & none \\
\hline PA0861 & PA14_53140 & $r b d A$ & GGDEF-EAL & + & none \\
\hline PA1107 & PA14_50060 & roeA & GGDEF & + & - \\
\hline PA1120 & PA14_49890 & $t p b B$ & GGDEF & + & none \\
\hline PA1181 & PA14_49160 & & GGDEF-EAL & + & + \\
\hline PA1433 & PA14_45930 & & GGDEF-EAL & + & none \\
\hline PA1727 & PA14_42220 & mucR & GGDEF-EAL & + & - \\
\hline PA1851 & PA14_40570 & & GGDEF & + & none \\
\hline PA2072 & PA14_37690 & & GGDEF-EAL & + & + \\
\hline PA2133 & PA14_36990 & & EAL & + & none \\
\hline PA2200 & PA14_36260 & & EAL & + & none \\
\hline PA2567 & PA14_31330 & & GGDEF-EAL & none & - \\
\hline PA2572 & PA14_30830 & & HD-GYP & + & + \\
\hline PA2870 & PA14_26970 & & GGDEF & + & + \\
\hline PA3177 & PA14_23130 & & GGDEF & none & + \\
\hline PA3258 & PA14_21870 & & GGDEF-EAL & none & none \\
\hline PA3311 & PA14_21190 & $n b d A$ & GGDEF-EAL & + & - \\
\hline PA3343 & PA14_20820 & $h s b D$ & GGDEF & + & - \\
\hline PA3702 & PA14_16500 & $w s p R$ & GGDEF & + & + \\
\hline PA3825 & PA14_14530 & & EAL & + & + \\
\hline PA3947 & PA14_12810 & roch & EAL & + & none \\
\hline PA4108 & PA14_10820 & & HD-GYP & + & none \\
\hline PA4332 & PA14_56280 & sadC & GGDEF & none & - \\
\hline PA4367 & PA14_56790 & bifA & GGDEF-EAL & + & - \\
\hline PA4396 & PA14_57140 & & GGDEF & none & none \\
\hline PA4601 & PA14_60870 & morA & GGDEF-EAL & + & - \\
\hline PA4781 & PA14_63210 & & HD-GYP & + & + \\
\hline PA4843 & PA14_64050 & $g c b A$ & GGDEF & none & + \\
\hline PA4929 & PA14_65090 & & GGDEF & + & - \\
\hline PA4959 & PA14_65540 & $\operatorname{fim} X$ & GGDEF-EAL & + & + \\
\hline PA5017 & PA14_66320 & $\operatorname{dip} A$ & GGDEF-EAL & none & - \\
\hline PA5295 & PA14_69900 & proE & GGDEF-EAL & + & none \\
\hline PA5442 & PA14_71850 & & GGDEF-EAL & - & - \\
\hline PA5487 & PA14_72420 & $d g c H$ & GGDEF & + & none \\
\hline * & PA14_59790 & $p v r R$ & EAL & none & none \\
\hline
\end{tabular}

* gene not present in PAO1

\section{Effects of endogenous or exogenous nitric oxide on nbdA expression}

380 In our previous study we observed elevated transcription levels of $n b d A$ in cells dispersed from biofilms after NO-treatment when compared to planktonically grown cells in RT-qPCR experiments (23). Therefore, we suggested transcriptional regulation of $n b d A$ by NO in this biofilm model. For $P$. aeruginosa two NO-responsive transcriptional regulators, FhpR and DNR are described. DNR is a heme-containing CRP/FNR type regulator that specifically activates denitrification genes under anaerobic conditions $(67,68)$. Transcription of the 
second NO responsive regulator in $P$. aeruginosa, FhpR, is $\sigma^{54}$-dependent and activates flavohemoglobin expression under aerobic conditions for the detoxification of $\mathrm{NO}$ in the cell $(42,43)$. When analyzing the reannotated $n b d A$ gene and promoter region, no similarity with either the FhpR or DNR consensus binding site was detected (69). Therefore, a direct influence of $\mathrm{NO}$ on $n b d A$ transcription was unlikely. These findings in addition to the contradictory results in the literature concerning the involvement of $\mathrm{NbdA}$ in $\mathrm{NO}$-induced biofilm dispersal of $P$. aeruginosa $(23,26)$ led to the reevaluation of the transcriptional regulation of $n b d A$ by $N O$. In this study, no direct stimulation of $n b d A$ promoter activity by $\mathrm{NO}$, neither by addition of exogenous NO nor by accumulation of intrinsic NO in planktonically grown cells was observed. The previously observed induction of $n b d A$ expression in our qRT-PCR experiments (23) might be due to more complex regulatory processes during biofilm formation and dispersal. From the present data, we conclude that $n b d A$ expression in planktonic cells is not directly induced by NO at the transcriptional level.

\section{Effect of the nitrite reductase NirS on $n b d A$ promoter activity}

In this study, we observed a strong increase in the $n b d A$ transcription level when the nitrite reductase NirS was deleted. At first, we assumed that the upregulation of $n b d A$ expression might be due to accumulation of intrinsic nitrite from interrupted denitrification. However, addition of nitrite to the growth medium did not change $n b d A$ promoter activity. Further, the $\Delta$ nirF strain producing an enzymatically inactive NirS protein (41) did not enhance $n b d A$ transcription. Therefore, we suggest that the presence of the periplasmic protein NirS affects $n b d A$ transcription independently of its enzymatic activity. The moonlighting role of NirS was previously described for the type III secretion system in P. aeruginosa (70). Additionally, NirS was shown to affect flagellum biogenesis by the formation of a complex with the flagellar subunit FliC and the chaperone $\operatorname{DnaK}(4,60,71)$. Suggesting this complex role for NirS besides denitrification in $P$. aeruginosa, the increase of $n b d A$ promoter activity in the $\Delta n i r S$ strain is probably derived from a global regulatory change in the cell.

All in all, we were able to reannotate the $n b d A$ gene and revealed consensus sequences for the alternative sigma factor RpoS and the transcription factor AmrZ within the $n b d A$ promoter region. Our data confirmed RpoS as activator and $A m r Z$ as repressor for $n b d A$ transcription, however, no transcriptional regulation by endogenous or exogenous NO or nitrite was observed in planktonically grown cells.

\section{AUTHORS STATEMENTS}

\section{Authors and contributors}

KG, SZ, NFD conceived the study, KG and SZ performed experiments, KG and SZ analyzed the data, $K G$ wrote first draft of manuscript, all authors revised and approved the final version of the manuscript.

\section{Conflict of interests}

The authors declare no conflict of interest.

\section{Funding information}

This work was funded by the SPP 1879 "Nucleotide Second Messenger Signaling in Bacteria" of the DFG.

\section{Acknowledgements}

We thank Sandra Schwarz (Tübingen, Germany) for the generous gift of the plasmid pEXG2. 


\section{REFERENCES}

431

432

433

434

435

436

437

438

439

440

441

442

443

444

445

446

447

448

449

450

451

452

453

454

455

456

457

458

459

460

461

462

463

464

465

466

467

468

469

470

471

472

473

474

475

476

477

478

479

480

481

1. Costerton JW, Stewart PS, Greenberg EP. Bacterial biofilms: a common cause of persistent infections. Science. 1999;284(5418):1318-22. doi:10.1126/science.284.5418.1318

2. del Pozo JL, Patel R. The challenge of treating biofilm-associated bacterial infections. Clinical Pharmacology \& Therapeutics. 2007;82(2):204-9. doi:10.1038/sj.clpt.6100247

3. Leid JG, Willson CJ, Shirtliff ME, Hassett DJ, Parsek MR, Jeffers AK. The exopolysaccharide alginate protects Pseudomonas aeruginosa biofilm bacteria from IFN-gamma-mediated macrophage killing. Journal of Immunology. 2005;175(11):7512-8. doi:10.4049/jimmunol.175.11.7512

4. Barraud N, Hassett DJ, Hwang SH, Rice SA, Kjelleberg S, Webb JS. Involvement of nitric oxide in biofilm dispersal of Pseudomonas aeruginosa. Journal of Bacteriology. 2006;188(21):7344-53. doi: $10.1128 / \mathrm{JB} .00779-06$

5. Huynh TT, McDougald D, Klebensberger J, Al Qarni B, Barraud N, Rice SA, et al. Glucose starvation-induced dispersal of Pseudomonas aeruginosa biofilms is CAMP and energy dependent. PLoS One. 2012;7(8):e42874. doi:10.1371/journal.pone.0042874

6. Sauer K, Cullen MC, Rickard AH, Zeef LA, Davies DG, Gilbert P. Characterization of nutrientinduced dispersion in Pseudomonas aeruginosa PAO1 biofilm. Journal of Bacteriology. 2004;186(21):7312-26. doi:10.1128/JB.186.21.7312-7326.2004

7. Sondermann H, Shikuma NJ, Yildiz FH. You've come a long way: c-di-GMP signaling. Current Opinion in Microbiology. 2012;15(2):140-6. doi:10.1016/i.mib.2011.12.008

8. Paul R, Weiser S, Amiot NC, Chan C, Schirmer T, Giese B, et al. Cell cycle-dependent dynamic localization of a bacterial response regulator with a novel di-guanylate cyclase output domain. Genes \& Development. 2004;18(6):715-27. doi:10.1101/gad.289504

9. Rao F, Yang Y, Qi Y, Liang ZX. Catalytic mechanism of cyclic di-GMP-specific phosphodiesterase: a study of the EAL domain-containing RocR from Pseudomonas aeruginosa. Journal of Bacteriology. 2008;190(10):3622-31. doi:10.1128/JB.00165-08

10. Ryjenkov DA, Tarutina M, Moskvin OV, Gomelsky M. Cyclic diguanylate is a ubiquitous signaling molecule in bacteria: insights into biochemistry of the GGDEF protein domain. Journal of Bacteriology. 2005;187(5):1792-8. doi:10.1128/JB.187.5.1792-1798.2005

11. Stelitano V, Giardina G, Paiardini A, Castiglione N, Cutruzzola F, Rinaldo S. C-di-GMP hydrolysis by Pseudomonas aeruginosa HD-GYP phosphodiesterases: analysis of the reaction mechanism and novel roles for pGpG. PLoS One. 2013;8(9):e74920. doi:10.1371/journal.pone.0074920

12. Tchigvintsev A, Xu X, Singer A, Chang C, Brown G, Proudfoot M, et al. Structural insight into the mechanism of c-di-GMP hydrolysis by EAL domain phosphodiesterases. Journal of Molecular Biology. 2010;402(3):524-38. doi:10.1016/i.jmb.2010.07.050

13. Hengge R. Principles of c-di-GMP signalling in bacteria. Nature Reviews Microbiology. 2009;7(4):263-73. doi:10.1038/nrmicro2109

14. Jonas K, Edwards AN, Simm R, Romeo T, Romling U, Melefors $O$. The RNA binding protein CsrA controls cyclic di-GMP metabolism by directly regulating the expression of GGDEF proteins. Molecular Microbiology. 2008;70(1):236-57. doi:10.1111/j.1365-2958.2008.06411.x

15. Moscoso JA, Jaeger T, Valentini M, Hui K, Jenal U, Filloux A. The diguanylate cyclase SadC is a central player in Gac/Rsm-mediated biofilm formation in Pseudomonas aeruginosa. Journal of Bacteriology. 2014;196(23):4081-8. doi:10.1128/JB.01850-14

16. Bellini D, Horrell S, Hutchin A, Phippen CW, Strange RW, Cai Y, et al. Dimerisation induced formation of the active site and the identification of three metal sites in EAL-phosphodiesterases. Scientific Reports. 2017;7:42166. doi:10.1038/srep42166

17. An S, Wu J, Zhang LH. Modulation of Pseudomonas aeruginosa biofilm dispersal by a cyclicDi-GMP phosphodiesterase with a putative hypoxia-sensing domain. Applied and Environmental Microbiology. 2010;76(24):8160-73. doi:10.1128/AEM.01233-10

18. Wassmann P, Chan C, Paul R, Beck A, Heerklotz H, Jenal U, et al. Structure of BeF3- modified response regulator PleD: implications for diguanylate cyclase activation, catalysis, and feedback inhibition. Structure. 2007;15(8):915-27. doi:10.1016/i.str.2007.06.016 
19. Tuckerman JR, Gonzalez G, Sousa EH, Wan X, Saito JA, Alam M, et al. An oxygen-sensing diguanylate cyclase and phosphodiesterase couple for c-di-GMP control. Biochemistry. 2009;48(41):9764-74. doi:10.1021/bi901409g

20. Paiardini A, Mantoni F, Giardina G, Paone A, Janson G, Leoni L, et al. A novel bacterial Iarginine sensor controlling c-di-GMP levels in Pseudomonas aeruginosa. Proteins. 2018;86(10):108896. doi:10.1002/prot.25587

21. Sarenko O, Klauck G, Wilke FM, Pfiffer V, Richter AM, Herbst S, et al. More than Enzymes That Make or Break Cyclic Di-GMP-Local Signaling in the Interactome of GGDEF/EAL Domain Proteins of Escherichia coli. mBio. 2017;8(5). doi:10.1128/mBio.01639-17

22. Kulasakara $\mathbf{H}$, Lee $\mathbf{V}$, Brencic A, Liberati N, Urbach J, Miyata S, et al. Analysis of Pseudomonas aeruginosa diguanylate cyclases and phosphodiesterases reveals a role for bis-(3'-5')cyclic-GMP in virulence. Proceedings of the National Academy of Sciences of the United States of America. 2006;103(8):2839-44. doi:10.1073/pnas.0511090103

23. Li Y, Heine S, Entian M, Sauer K, Frankenberg-Dinkel N. NO-induced biofilm dispersion in Pseudomonas aeruginosa is mediated by an MHYT domain-coupled phosphodiesterase. Journal of Bacteriology. 2013;195(16):3531-42. doi:10.1128/JB.01156-12

24. Galperin MY, Gaidenko TA, Mulkidjanian AY, Nakano M, Price CW. MHYT, a new integral membrane sensor domain. FEMS Microbiology Letters. 2001;205(1):17-23. doi:10.1111/j.15746968.2001.tb10919.x

25. Roy AB, Petrova OE, Sauer K. The phosphodiesterase DipA (PA5017) is essential for Pseudomonas aeruginosa biofilm dispersion. Journal of Bacteriology. 2012;194(11):2904-15. doi:10.1128/JB.05346-11

26. Zemke AC, D'Amico EJ, Snell EC, Torres AM, Kasturiarachi N, Bomberger JM. Dispersal of Epithelium-Associated Pseudomonas aeruginosa Biofilms. mSphere. 2020;5(4). doi: $\underline{10.1128 / \mathrm{mSphere} .00630-20}$

27. Hanahan D. Studies on transformation of Escherichia coli with plasmids. Journal of Molecular Biology. 1983;166(4):557-80. doi:10.1016/s0022-2836(83)80284-8

28. de Lorenzo V, Timmis KN. Analysis and construction of stable phenotypes in gram-negative bacteria with Tn5- and Tn10-derived minitransposons. Methods in Enzymology. 1994;235:386-405. doi:10.1016/0076-6879(94)35157-0

29. Rietsch A, Vallet-Gely I, Dove SL, Mekalanos JJ. ExsE, a secreted regulator of type III secretion genes in Pseudomonas aeruginosa. Proceedings of the National Academy of Sciences of the United States of America. 2005;102(22):8006-11. doi:10.1073/pnas.0503005102

30. Becher A, Schweizer HP. Integration-proficient Pseudomonas aeruginosa vectors for isolation of single-copy chromosomal lacZ and lux gene fusions. Biotechniques. 2000;29(5):948-50, 52. doi: $10.2144 / 00295 \mathrm{bm} 04$

31. Hmelo LR, Borlee BR, Almblad H, Love ME, Randall TE, Tseng BS, et al. Precision-engineering the Pseudomonas aeruginosa genome with two-step allelic exchange. Nature Protocols. 2015;10(11):1820-41. doi:10.1038/nprot.2015.115

32. Miller JH. Experiments in molecular genetics. Cold Spring Harbor: Cold Spring Harbor Laboratory Press; 1972.

33. Hauser F, Pessi G, Friberg M, Weber C, Rusca N, Lindemann A, et al. Dissection of the Bradyrhizobium japonicum NifA+sigma54 regulon, and identification of a ferredoxin gene $(f d x N)$ for symbiotic nitrogen fixation. Molecular Genetics and Genomics. 2007;278(3):255-71. doi:10.1007/s00438-007-0246-9

34. Jones CJ, Newsom D, Kelly B, Irie Y, Jennings LK, Xu B, et al. ChIP-Seq and RNA-Seq reveal an AmrZ-mediated mechanism for cyclic di-GMP synthesis and biofilm development by Pseudomonas aeruginosa. PLoS Pathogens. 2014;10(3):e1003984. doi:10.1371/journal.ppat.1003984

35. Schulz S, Eckweiler D, Bielecka A, Nicolai T, Franke R, Dotsch A, et al. Elucidation of sigma factor-associated networks in Pseudomonas aeruginosa reveals a modular architecture with limited and function-specific crosstalk. PLoS Pathogens. 2015;11(3):e1004744. doi:10.1371/journal.ppat.1004744 
36. Winsor GL, Griffiths EJ, Lo R, Dhillon BK, Shay JA, Brinkman FS. Enhanced annotations and features for comparing thousands of Pseudomonas genomes in the Pseudomonas genome database. Nucleic Acids Research. 2016;44(D1):D646-53. doi:10.1093/nar/gkv1227

37. James GA, Ge Zhao A, Usui M, Underwood RA, Nguyen H, Beyenal $H$, et al. Microsensor and transcriptomic signatures of oxygen depletion in biofilms associated with chronic wounds. Wound Repair and Regeneration. 2016;24(2):373-83. doi:10.1111/wrr.12401

38. Denis M. Human monocytes/macrophages: NO or no NO? Journal of Leukocyte Biology. 1994;55(5):682-4. doi:10.1002/jlb.55.5.682

39. Cutruzzola F, Frankenberg-Dinkel N. Origin and Impact of Nitric Oxide in Pseudomonas aeruginosa Biofilms. Journal of Bacteriology. 2016;198(1):55-65. doi:10.1128/JB.00371-15

40. Ye RW, Averill BA, Tiedje JM. Denitrification: production and consumption of nitric oxide. Applied and Environmental Microbiology. 1994;60(4):1053-8. doi:10.1128/AEM.60.4.1053-1058.1994 41. Nicke T, Schnitzer T, Munch K, Adamczack J, Haufschildt K, Buchmeier S, et al. Maturation of the cytochrome cd1 nitrite reductase NirS from Pseudomonas aeruginosa requires transient interactions between the three proteins NirS, NirN and NirF. Bioscience Reports. 2013;33(3). doi:10.1042/BSR20130043

42. Arai HH, M.; Kuroi, A.; Ishii, M.; Igarashi, Y. Transcriptional regulation of the flavohemoglobin gene for aerobic nitric oxide detoxification by the second nitric oxide-responsive regulator of Pseudomonas aeruginosa. Journal of Bacteriology. 2005;187(12):3960-8. doi:10.1128/JB.187.12.3960-3968.2005

43. Forrester MT, Foster MW. Protection from nitrosative stress: a central role for microbial flavohemoglobin. Free Radical Biology and Medicine. 2012;52(9):1620-33. doi:10.1016/i.freeradbiomed.2012.01.028

44. Fujita M, Tanaka K, Takahashi $\mathbf{H}$, Amemura A. Transcription of the principal sigma-factor genes, rpoD and rpoS, in Pseudomonas aeruginosa is controlled according to the growth phase. Molecular Microbiology. 1994;13(6):1071-7. doi:10.1111/i.1365-2958.1994.tb00498.x

45. Jorgensen F, Bally $M$, Chapon-Herve V, Michel G, Lazdunski A, Williams $P$, et al. RpoSdependent stress tolerance in Pseudomonas aeruginosa. Microbiology (Reading). 1999;145 ( Pt 4):835-44. doi:10.1099/13500872-145-4-835

46. Landini P, Egli T, Wolf J, Lacour S. sigmaS, a major player in the response to environmental stresses in Escherichia coli: role, regulation and mechanisms of promoter recognition. Environmental Microbiology Reports. 2014;6(1):1-13. doi:10.1111/1758-2229.12112

47. Dong T, Schellhorn HE. Role of RpoS in virulence of pathogens. Infection and Immunity. 2010;78(3):887-97. doi: $10.1128 /$ IAl.00882-09

48. Guan J, Xiao X, Xu S, Gao F, Wang J, Wang T, et al. Roles of RpoS in Yersinia pseudotuberculosis stress survival, motility, biofilm formation and type $\mathrm{VI}$ secretion system expression. Journal of Microbiology. 2015;53(9):633-42. doi:10.1007/s12275-015-0099-6

49. Tian Y, Wang Q, Liu Q, Ma Y, Cao X, Zhang Y. Role of RpoS in stress survival, synthesis of extracellular autoinducer 2, and virulence in Vibrio alginolyticus. Archives of Microbiology. 2008;190(5):585-94. doi:10.1007/s00203-008-0410-6

50. Yildiz FH, Schoolnik GK. Role of rpoS in stress survival and virulence of Vibrio cholerae. Journal of Bacteriology. 1998;180(4):773-84. doi:10.1128/JB.180.4.773-784.1998

51. Adams JL, McLean RJ. Impact of rpoS deletion on Escherichia coli biofilms. Applied and Environmental Microbiology. 1999;65(9):4285-7. doi:10.1128/AEM.65.9.4285-4287.1999

52. Ito A, May T, Kawata K, Okabe S. Significance of rpoS during maturation of Escherichia coli biofilms. Biotechnology and Bioengineering. 2008;99(6):1462-71. doi:10.1002/bit.21695

53. Mika F, Hengge R. Small RNAs in the control of RpoS, CsgD, and biofilm architecture of Escherichia coli. RNA Biology. 2014;11(5):494-507. doi:10.4161/rna.28867

54. Sommerfeldt N, Possling A, Becker G, Pesavento C, Tschowri N, Hengge R. Gene expression patterns and differential input into curli fimbriae regulation of all GGDEF/EAL domain proteins in Escherichia coli. Microbiology (Reading). 2009;155(Pt 4):1318-31. doi:10.1099/mic.0.024257-0 
55. Weber H, Pesavento C, Possling A, Tischendorf G, Hengge R. Cyclic-di-GMP-mediated signalling within the sigma network of Escherichia coli. Molecular Microbiology. 2006;62(4):1014-34. doi:10.1111/j.1365-2958.2006.05440.x

56. Heydorn A, Ersboll B, Kato J, Hentzer M, Parsek MR, Tolker-Nielsen T, et al. Statistical analysis of Pseudomonas aeruginosa biofilm development: impact of mutations in genes involved in twitching motility, cell-to-cell signaling, and stationary-phase sigma factor expression. Applied and Environmental Microbiology. 2002;68(4):2008-17. doi:10.1128/aem.68.4.2008-2017.2002 57. Whiteley M, Bangera MG, Bumgarner RE, Parsek MR, Teitzel GM, Lory S, et al. Gene expression in Pseudomonas aeruginosa biofilms. Nature. 2001;413(6858):860-4. doi:10.1038/35101627

58. Irie Y, Starkey M, Edwards AN, Wozniak DJ, Romeo T, Parsek MR. Pseudomonas aeruginosa biofilm matrix polysaccharide Psl is regulated transcriptionally by RpoS and post-transcriptionally by RsmA. Molecular Microbiology. 2010;78(1):158-72. doi:10.1111/j.1365-2958.2010.07320.x

59. Liu H, Yan $\mathbf{H}$, Xiao $\mathbf{Y}$, Nie $\mathbf{H}$, Huang $\mathbf{Q}$, Chen $\mathbf{W}$. The exopolysaccharide gene cluster pea is transcriptionally controlled by RpoS and repressed by AmrZ in Pseudomonas putida KT2440. Microbiological Research. 2019;218:1-11. doi:10.1016/j.micres.2018.09.004

60. Borrero-de Acuna JM, Timmis KN, Jahn M, Jahn D. Protein complex formation during denitrification by Pseudomonas aeruginosa. Microbial Biotechnology. 2017;10(6):1523-34. doi:10.1111/1751-7915.12851

61. Wozniak DJ, Sprinkle AB, Baynham PJ. Control of Pseudomonas aeruginosa algZ expression by the alternative sigma factor AlgT. Journal of Bacteriology. 2003;185(24):7297-300. doi:10.1128/jb.185.24.7297-7300.2003

62. Baynham PJ, Brown AL, Hall LL, Wozniak DJ. Pseudomonas aeruginosa AlgZ, a ribbon-helixhelix DNA-binding protein, is essential for alginate synthesis and $\operatorname{alg} D$ transcriptional activation. Molecular Microbiology. 1999;33(5):1069-80. doi:10.1046/j.1365-2958.1999.01550.x

63. Baynham PJ, Ramsey DM, Gvozdyev BV, Cordonnier EM, Wozniak DJ. The Pseudomonas aeruginosa ribbon-helix-helix DNA-binding protein AlgZ (AmrZ) controls twitching motility and biogenesis of type IV pili. Journal of Bacteriology. 2006;188(1):132-40. doi:10.1128/JB.188.1.132$\underline{140.2006}$

64. Xu A, Zhang M, Du W, Wang D, Ma LZ. A molecular mechanism for how sigma factor AlgT and transcriptional regulator AmrZ inhibit twitching motility in Pseudomonas aeruginosa. Environmental Microbiology. 2020. doi:10.1111/1462-2920.14985

65. Muriel C, Arrebola E, Redondo-Nieto M, Martinez-Granero F, Jalvo B, Pfeilmeier S, et al. AmrZ is a major determinant of c-di-GMP levels in Pseudomonas fluorescens F113. Scientific Reports. 2018;8(1):1979. doi:10.1038/s41598-018-20419-9

66. Xu B, Ju Y, Soukup RJ, Ramsey DM, Fishel R, Wysocki VH, et al. The Pseudomonas aeruginosa AmrZ C-terminal domain mediates tetramerization and is required for its activator and repressor functions. Environmental Microbiology Reports. 2016;8(1):85-90. doi:10.1111/1758$\underline{2229.12354}$

67. Arai $\mathbf{H}$, Igarashi $\mathbf{Y}$, Kodama T. Expression of the nir and nor genes for denitrification of Pseudomonas aeruginosa requires a novel CRP/FNR-related transcriptional regulator, DNR, in addition to ANR. FEBS Letters. 1995;371(1):73-6. doi:10.1016/0014-5793(95)00885-d

68. Trunk K, Benkert B, Quack N, Munch R, Scheer M, Garbe J, et al. Anaerobic adaptation in Pseudomonas aeruginosa: definition of the Anr and Dnr regulons. Environmental Microbiology. 2010;12(6):1719-33. doi:10.1111/j.1462-2920.2010.02252.x

69. Rodionov DA, Dubchak IL, Arkin AP, Alm EJ, Gelfand MS. Dissimilatory metabolism of nitrogen oxides in bacteria: comparative reconstruction of transcriptional networks. PLOS Computational Biology. 2005;1(5):e55. doi:10.1371/journal.pcbi.0010055

70. Van Alst NE, Wellington M, Clark VL, Haidaris CG, Iglewski BH. Nitrite reductase NirS is required for type III secretion system expression and virulence in the human monocyte cell line THP1 by Pseudomonas aeruginosa. Infection and Immunity. 2009;77(10):4446-54. doi:10.1128/IAI.00822$\underline{09}$ 
bioRxiv preprint doi: https://doi.org/10.1101/2021.03.31.437996; this version posted April 1, 2021. The copyright holder for this preprint (which was not certified by peer review) is the author/funder, who has granted bioRxiv a license to display the preprint in perpetuity. It is made available under aCC-BY 4.0 International license.

637 71. Borrero-de Acuna JM, Molinari G, Rohde M, Dammeyer T, Wissing J, Jansch L, et al. A 638 Periplasmic Complex of the Nitrite Reductase NirS, the Chaperone DnaK, and the Flagellum Protein 639 FliC Is Essential for Flagellum Assembly and Motility in Pseudomonas aeruginosa. Journal of 640 Bacteriology. 2015;197(19):3066-75. doi:10.1128/JB.00415-15

641 